\title{
Percepção de graduandos em Educação Física sobre as aulas remotas frente à COVID-19: Um estudo de caso
}

\author{
Perception of Physical Education students about remote classes in front of COVID-19: A case study \\ La percepción de estudiantes universitários de Educación Física de las clases remotas frente a \\ COVID-19: Un estudio de caso
}

Recebido: 12/03/2021 | Revisado: 20/03/2021 | Aceito: 21/03/2021 | Publicado: 29/03/2021

\author{
Vivian de Oliveira \\ ORCID: https://orcid.org/0000-0001-9558-3488 \\ Centro Universitário Instituto de Educação Superior de Brasília, Brasil \\ E-mail: vivian_oliveira58@hotmail.com \\ Ivan Wallan Tertuliano \\ ORCID: https://orcid.org/0000-0001-6413-6888 \\ Universidade Anhembi Morumbi, Brasil \\ E-mail: ivanwallan@gmail.com \\ Sérgio Avelino da Silva \\ ORCID: https://orcid.org/0000-0002-8761-5766 \\ Centro Universitário Instituto de Educação Superior de Brasília, Brasil \\ E-mail: sergio.avelino@iesb.br \\ Henrique de Oliveira Castro \\ ORCID: https://orcid.org/0000-0002-0545-164X \\ Universidade Federal do Mato Grosso, Brasil \\ E-mail: henriquecastro88@yahoo.com.br
}

\begin{abstract}
Resumo
Frente a COVID-19, muitas Instituições de Ensino Superior ao redor do mundo adotaram o ensino online como uma estratégia para a manutenção das atividades acadêmicas. Neste sentido, o objetivo do presente estudo foi apontar a percepção de discentes de Educação Física sobre as aulas remotas. Participaram do estudo 92 estudantes do curso presencial de graduação em Educação Física de uma Instituição de Ensino Superior privada, com média de idade de $25,07( \pm 8,31)$ anos. A coleta dos dados foi feita por meio de um formulário no Google Forms®. De acordo com os resultados, os discentes acreditam que a adoção das aulas remotas foi uma boa decisão da instituição, assim como avaliam positiva a adaptação dos professores. As dificuldades apontadas pelos discentes envolvem problemas de conexão à internet, questões pessoais, financeiras e de adaptação ao novo modelo. Assim, destaca-se a importância da capacitação de docentes para o ensino online, assim como do apoio da instituição aos discentes que enfrentam problemas no processo, além da necessidade de novos estudos na área.
\end{abstract}

Palavras-chave: Ensino remoto; Ensino superior; Educação física; Ensino à distância; COVID-19.

\begin{abstract}
In face of COVID-19, many universities all over the word have adopted the online learning as a strategy for maintaining academic activities. In the sense, the aim of this study was to point the perception Physical Education students about remote classes. A total of 92 students from the physical education course in a private higher education institution participated in the study, with an average age of $25.07( \pm 8.31)$ years. The data was collected through a form in Google Forms ${ }^{\circledR}$. According to the results, the students believe that the adoption of remote classes was a good decision by the institution, and evaluated the adaptation of teachers as positive. The difficulties pointed out by the students involve problems with internet connection, personal, financial issues and adaptation to the new model. Thus, the importance of teacher training for online teaching is highlighted, as well as the institution's support for students who face problems in the process, in addition to the need for further studies in the area.
\end{abstract}

Keywords: Remote teaching; University education; Physical education; Distance learning; COVID-19.

\section{Resumen}

Frente a COVID-19, muchas Instituciones de Educación Superior en todo el mundo han adoptado las clases online como una estrategia para mantener las actividades académicas. En este sentido, el objetivo de este estudio fue apuntar la percepción de los estudiantes del curso de Educación Física sobre las clases remotas. Participaron en el estudio 92 estudiantes del curso de grado en Educación Física en una institución privada de educación superior, con una edad promedio de 25.07 ( \pm 8.31) años. La recogida de datos se realizó mediante un formulario en Google Forms®. Según los resultados, los estudiantes creen que la adopción de clases remotas fue una buena decisión de la institución, así 
como evalúan la adaptación de los docentes positiva. Las dificultades señaladas por los estudiantes involucran problemas con la conexión a internet, cuestiones personales, financieras y de la adaptación al nuevo modelo. Por lo tanto, se destaca la importancia de la capacitación de los docentes para la enseñanza online, así como del apoyo de la institución a los estudiantes que enfrentan problemas en el proceso, así como la necesidad de nuevos estudios en área.

Palabras clave: Enseñanza remota; Enseñanza superior; Educación física; Educación a distancia; COVID-19.

\section{Introduçãa}

A COVID-19 é o nome da doença causada pelo coronavírus SARS-CoV-2, caracterizada por um quadro clínico que pode variar entre infecções assintomáticas a quadros respiratórios graves (Ministério da Saúde, 2020). Em 11 de março de 2020, a COVID-19 foi caracterizada pela Organização Mundial da Saúde (OMS) como uma pandemia, e desde então, o isolamento social tem sido apontado como uma das medidas de grande eficácia para a diminuição da transmissão do vírus, diminuindo assim o número de infectados e, consequentemente, o de óbitos (Center for Disease and Prevention, 2019; Cetron \& Simone, 2004; Lewnard \& Lo, 2020).

Frente às recomendações, as atividades consideradas não essenciais foram suspensas em diversos países (WilderSmith \& Freedman, 2020). As atividades acadêmicas, na educação infantil quanto no ensino básico e superior, foram algumas das primeiras atividades a serem suspensas. Assim, muitas das instituições de ensino superior (IES), em especial as privadas, adotaram o sistema remoto para as aulas. Perante este cenário, discute-se, de forma intensa, sobre a educação a distância, as aulas remotas, e os ambientes virtuais de aprendizagem (AVAs).

Desde a criação da Internet e a evolução de suas ferramentas, assim como das Tecnologias de Informação e Comunicação (TICs), houve um aumento na utilização da comunicação online, tanto a comunicação síncrona quanto da assíncrona. Essas novas possibilidades fizeram com que a educação também sofresse consequências, possibilitando, por exemplo, o surgimento do ensino online (aqui tratado como ensino remoto).

É importante definir alguns dos conceitos oriundos da educação online. A Educação a Distância (EaD) é definida pelo Decreto $n^{\circ}$. 9.057, de 25 de maio de 2017, como "a modalidade educacional na qual a mediação didático-pedagógica nos processos de ensino e aprendizagem ocorra com a utilização de meios e tecnologias de informação e comunicação, com pessoal qualificado, com políticas de acesso, com acompanhamento e avaliação compatíveis, entre outros, e desenvolva atividades educativas por estudantes e profissionais da educação que estejam em lugares e tempos diversos" (Brasil, 2017, p. $03)$.

Neste sentido, Santos (2017) complementa que o ensino remoto, conceito mais abrangente, não significa apenas educação a distância, mas uma modalidade de educação, que pode ser utilizada para complementar as situações de aprendizagem que acontecem de modo presencial. Além disso, o ensino remoto pode ser utilizado no caso de impedimentos para que os indivíduos possam se encontrar presencialmente, ou pode ainda ser híbrida, onde os encontros presenciais são combinados com encontros por meio das ferramentas digitais (Rasheed et al., 2020; Santos, 2017).

O ensino remoto, por sua vez, traz algumas peculiaridades, e segundo Barbosa et al. (2020), implica em novas formas de difundir o conhecimento e de divulgar conteúdos por meio de plataformas digitais online. Para Silva et al. (2020), este tipo de ensino envolve a utilização de estratégias de ensino remoto, onde o aluno participa da aula de onde estiver, basta ter acesso a um dispositivo com internet, para aulas que, anteriormente eram desenvolvidas de forma presencial, gerando uma mudança momentânea, objetivando a transmissão, de forma online, de conteúdos curriculares.

Para Barbosa et al. (2020), o modelo de ensino remoto envolve uma série de novos desafios para as instituições, para os docentes, discentes, corpo administrativo e outros personagens neste cenário. Isso porque, segundo os autores, as dinâmicas das novas ferramentas são impostas a pessoas que, muitas vezes, não as dominam. Konrath et al. (2009) destacam ainda que, para os cursos que podem ser acessados e realizados de forma online (como o ensino remoto) garantam a qualidade, eles não 
podem ser uma cópia do presencial, ou seja, não é possível apenas realizar da mesma forma que do modo presencial para o ambiente virtual.

Assim, o objetivo do presente estudo foi apontar a percepção de universitários do curso de graduação em Educação Física de uma Instituição de Ensino Superior privada sobre as aulas remotas, adotadas frente a suspensão das atividades presenciais ocasionada pela COVID-19.

\section{Metodologia}

Esta apresenta-se como uma pesquisa qualitativa, de caráter descritiva, que se configura como um estudo de caso (André, 2013; Stake, 2011). Participaram do estudo 92 estudantes do curso presencial de graduação em Educação Física (Licenciatura e Bacharelado) de uma Instituição de Ensino Superior privada, sendo 65 homens e 27 mulheres, com média de idade de 25,07 ( \pm 8,31) anos. Dos estudantes que responderam à pesquisa, 32 eram do $1^{\circ}$ semestre do curso, seis do $2^{\circ}, 19$ do $3^{\circ}$, dois do $4^{\circ}$, cinco do $5^{\circ}$, cinco do $6^{\circ}$, nove do $7^{\circ}$ e 14 do $8^{\circ}$.

Para coleta dos dados, foi criado pelos próprios autores um questionário, convertido em um formulário do Google Forms ${ }^{\circledR}$. As questões que compuseram o instrumento desse estudo, assim como as opções de respostas, foram elaboradas pelos autores tendo como base os relatos informais dos professores da instituição em questão, sobre as primeiras percepções proferidas em sala pelos discentes sobre as aulas remotas. O questionário é composto por três partes: a primeira, contendo o Termo de Consentimento Livre e Esclarecido, que viabiliza a participação no estudo e o encaminha para as próximas etapas; a segunda, composta por quatro perguntas destinadas à caracterização da amostra (nome, idade, sexo e semestre) e; a terceira parte do questionário contém 17 perguntas específicas, três abertas e 14 fechadas, em concordância com o objetivo deste estudo. Das 14 perguntas fechadas, cinco eram de múltipla-escolha e nove dicotômicas (Mattar, 1996), com possibilidades de resposta "sim" e "não". As questões que compõe o questionário utilizado para o estudo estão descritas no Quadro 1.

Quadro 1. Apresentação das questões do questionário.

\begin{tabular}{|c|c|}
\hline \multicolumn{2}{|l|}{ Primeira Parte } \\
\hline 1. Apresentação do Termo de Consentimento Livre e Esclarecido e declaração de aceite & $\begin{array}{c}\text { Questão fechada } \\
\text { (dicotômica) }\end{array}$ \\
\hline \multicolumn{2}{|l|}{ Segunda Parte } \\
\hline 1. Nome & Questão aberta \\
\hline 2. Idade & Questão aberta \\
\hline 3. Sexo & $\begin{array}{l}\text { Questão fechada } \\
\text { (dicotômica) }\end{array}$ \\
\hline 4. Semestre em que está matriculado & $\begin{array}{l}\text { Questão fechada } \\
\text { (múltipla-escolha) }\end{array}$ \\
\hline \multicolumn{2}{|l|}{ Terceira Parte } \\
\hline $\begin{array}{c}\text { 1. A decisão da instituição em manter o calendário acadêmico com as aulas remotas foi } \\
\text { uma boa opção? }\end{array}$ & $\begin{array}{l}\text { Questão fechada } \\
\text { (dicotômica) }\end{array}$ \\
\hline $\begin{array}{c}\text { 2. De forma geral, os professores conseguiram adaptar bem o conteúdo para as aulas } \\
\text { remotas? }\end{array}$ & $\begin{array}{l}\text { Questão fechada } \\
\text { (dicotômica) }\end{array}$ \\
\hline $\begin{array}{l}\text { 3. De forma geral, os professores conseguiram se adaptar de forma satisfatória ao uso dos } \\
\text { ambientes virtuais de aprendizagem? }\end{array}$ & $\begin{array}{l}\text { Questão fechada } \\
\text { (dicotômica) }\end{array}$ \\
\hline
\end{tabular}




\begin{tabular}{|c|c|}
\hline 4. De forma geral, as aulas remotas são atrativas? & $\begin{array}{l}\text { Questão fechada } \\
\text { (dicotômica) }\end{array}$ \\
\hline 5. O seu interesse em acompanhar as aulas remotas diminuiu ao longo do tempo? & $\begin{array}{l}\text { Questão fechada } \\
\text { (dicotômica) }\end{array}$ \\
\hline $\begin{array}{l}\text { 6. Quando não consegue estar presente em uma aula remota no horário em que ela } \\
\text { acontece, você costuma assistir as gravações posteriormente? }\end{array}$ & $\begin{array}{l}\text { Questão fechada } \\
\text { (dicotômica) }\end{array}$ \\
\hline $\begin{array}{l}\text { 7. O fato de saber que a gravação estará disponível posteriormente já te desmotivou a } \\
\text { assistir uma aula remota ao vivo? }\end{array}$ & $\begin{array}{l}\text { Questão fechada } \\
\text { (dicotômica) }\end{array}$ \\
\hline $\begin{array}{l}\text { 8. Você acredita que a sua formação ficará prejudicada de alguma forma por causa da } \\
\text { adoção das aulas remotas? }\end{array}$ & $\begin{array}{l}\text { Questão fechada } \\
\text { (dicotômica) }\end{array}$ \\
\hline 9. Caso tenha respondido "SIM" na questão anterior, diga o porquê. & Questão aberta \\
\hline 10. Qual(quais) equipamento(s) que você utiliza para acompanhar as aulas remotas? & $\begin{array}{l}\text { Questão fechada } \\
\text { (múltipla-escolha) }\end{array}$ \\
\hline 11. De qual(quais) local(locais) você costuma acompanhar as aulas remotas? & $\begin{array}{l}\text { Questão fechada } \\
\text { (múltipla-escolha) }\end{array}$ \\
\hline $\begin{array}{l}\text { 12. Qual(quais) foi(foram) a(s) sua(s) maior(es) dificuldade(s) para acompanhar as aulas } \\
\text { remotas? }\end{array}$ & $\begin{array}{l}\text { Questão fechada } \\
\text { (múltipla-escolha) }\end{array}$ \\
\hline $\begin{array}{l}\text { 13. Você pensou em trancar a matrícula ou desistir do curso durante o período de aulas } \\
\text { remotas? }\end{array}$ & $\begin{array}{l}\text { Questão fechada } \\
\text { (dicotômica) }\end{array}$ \\
\hline 14. Qual foi sua maior dificuldade para os estudos durante o período de aulas remotas? & $\begin{array}{l}\text { Questão fechada } \\
\text { (múltipla-escolha) }\end{array}$ \\
\hline $\begin{array}{l}\text { 15. Você conseguiu entregar todas as atividades propostas pelos professores no período das } \\
\text { aulas remotas, assim como realizar as avaliações? Caso não tenha conseguido, quais } \\
\text { foram os motivos? }\end{array}$ & $\begin{array}{l}\text { Questão fechada } \\
\text { (múltipla-escolha) }\end{array}$ \\
\hline $\begin{array}{c}\text { 16. Quais são os pontos positivos das aulas remotas, quando comparadas às aulas } \\
\text { presenciais? }\end{array}$ & Questão aberta \\
\hline $\begin{array}{l}\text { 17. Quais são os pontos negativos das aulas remotas, quando comparadas às aulas } \\
\text { presenciais? }\end{array}$ & Questão aberta \\
\hline
\end{tabular}

Fonte: Autores.

O formulário foi enviado aos estudantes por meio de grupos do WhatsApp ${ }^{\circledR}$, e ficou disponível para os discentes durante duas semanas, entre 05 e 17 de maio de 2020. Os procedimentos para a coleta de dados foram delineados em concordância com as normas estabelecidas pelo Conselho Nacional de Saúde (Res. CNS 196/96) e com os padrões éticos da Declaração de Helsinque para estudos com seres humanos.

Todas respostas do questionário foram tabuladas em uma planilha, utilizando-se o software Excel® 2003. Em seguida, realizou-se uma análise descritiva dos dados, e as questões abertas foram categorizadas (Bardin, 2010). 


\section{Resultados e Discussão}

O presente estudo objetivou analisar a percepção de universitários do curso de graduação em Educação Física de uma Instituição de Ensino Superior sobre as aulas remotas, adotadas frente a suspensão das atividades presenciais ocasionada pela COVID-19.

A primeira pergunta da parte específica do questionário questionava sobre a adoção do ensino remoto. Quando perguntados se a decisão da instituição em manter o calendário acadêmico com as aulas remotas foi uma boa opção, 78 discentes $(84,8 \%)$ responderam que sim, enquanto 14 discentes $(15,2 \%)$ responderam que não. Sobre o trabalho do corpo docente, especificamente, a maioria dos discentes $(\mathrm{n}=81 ; 88 \%)$ consideram que os professores conseguiram adaptar bem o conteúdo para as aulas remotas, assim como a maior parte dos discentes $(n=83 ; 90,2 \%)$ também declarou que os docentes conseguiram se adaptar de forma satisfatória ao uso dos ambientes virtuais de aprendizagem.

Diante dos resultados apresentados, é interessante notar que alguns discentes ainda consideram as dificuldades dos professores nesse processo. Neste sentido, Barbosa et al. (2020) apontam para a dificuldade imposta aos docentes diante deste cenário, onde grandes mudanças em suas formas de trabalhos tiveram que acontecer em tão pouco tempo. Os autores destacam que para uma boa parte dos discentes, a utilização das ferramentas digitais, dos aparatos eletrônicos e das TICs é parte do cotidiano, enquanto os docentes tiveram que repensar novas possibilidades perante às novas tecnologias, não só do ponto de vista técnico (utilização das ferramentas, dos aplicativos e etc.), mas da criação de novas formas de ensinar os conteúdos pretendidos.

Além disso, destacam-se as limitações relacionadas ao funcionamento dos equipamentos e dispositivos, às conexões, as habilitações de dispositivos, equipamentos que suportem as instalações, a segurança de dados e as informações tornam essenciais à capacitação destes profissionais. Schimiguel et al. (2020) reforçam essa ideia, afirmando que a situação causada pela COVID-19 ocasionou um impacto importante no sistema educacional brasileiro, e fez necessária uma reflexão sobre os processos e estratégias educativas utilizadas pelos professores, fazendo com que estes profissionais precisassem aprender novas habilidades relacionadas com a questão do tempo, a motivação e criação de uma experiência mais agradável ao aluno, tornando-o mais preparado para os desafios do ensino remoto neste contexto

Sobre estas questões, os resultados do presente estudo nos mostraram que, no total, 54 discentes $(58,7 \%)$ responderam que consideram as aulas remotas atrativas, enquanto 38 (41,3\%) não as consideram. Além disso, 48 discentes (52,2\%) disseram que vivenciaram uma diminuição do interesse em acompanhar as aulas remotas ao longo do tempo, enquanto 44 $(47,8 \%)$ não tiveram a mesma percepção. Os resultados podem indicar outra dificuldade dos professores para a adaptação ao ensino remoto: o de tornar as aulas atrativas.

Como consequência da evolução das ferramentas tecnológicas destinadas à educação, das TICs e da facilidade de acesso à internet, a forma de aprender também evoluiu. Aprender não é mais uma tarefa que envolve a memorização, gravação de conteúdos e obter o conhecimento de uma forma passiva, e, portanto, é importante que os professores repensem o processo de ensino-aprendizagem, assumindo novas posturas. Em uma era cada vez mais conectada, é necessário que o docente desenvolva novas competências profissionais, para melhor rendimento no ensino remoto, desempenhando seu papel e buscando a criação de uma rede interativa, onde o conhecimento seja o eixo central (Konrath et al., 2009).

Nota-se uma certa dificuldade por parte dos docentes em adaptar os conteúdos ao ensino remoto, e muitos deles transmitem para os AVAs as práticas expositivas centralizadas no professor, com pouca interação, característica ainda marcante no ensino presencial. Portanto, para que o professor atue em AVA, é necessária maior dedicação do docente, apoio da equipe técnico-pedagógica, mais dispêndio de tempo para preparação, assim como para acompanhamento (Moran, 2012). Isso implica também no apoio e incentivo da instituição com a disposição de mais tempo livre para os docentes possam obter essas capacitações e se dedicarem mais. Konrath et al. (2009) citam a importância da capacitação de professores para o ensino 
remoto, enfatizando que estas devem oportunizar de o professor assumir o papel do aluno, para vivenciar seus desafios e dificuldades, além de apropriarem-se dos recursos tecnológicos, das plataformas e meios de comunicação disponíveis para o curso, corroborando com Rasheed et al. (2020).

Neste sentido, Konrath et al. (2009) complementam os apontamentos citando que a educação remota é bastante complexa, tão ou mais que o ensino presencial, e que para que ela tenha qualidade, é necessária uma organização que começa na proposta, e segue até a prática, pensando na estrutura, nos recursos humanos utilizados, no material didático, nos planos de ensino e de aulas, na estrutura administrativa.

Assim, frente a suspensão das atividades presenciais e a rápida adoção das aulas remotas por parte das IES, nota-se que o processo de preparação e planejamento para o ensino online precisa de ajustes. Porém, Silva (2012) destaca que não são apenas os docentes os responsáveis pelo sucesso do ensino remoto, os discentes precisam assimilar quais são seus papéis neste cenário, sabendo que serão mais exigidos, pois em uma sala de aula interativa é necessária a participação ativa dos discentes.

No presente estudo, foi questionado se os discentes costumam assistir posteriormente às gravações das aulas remotas, quando não conseguem estar presentes de forma síncrona. Para esta questão, 59 discentes $(64,1 \%)$ disseram que sim, enquanto $33(35,9 \%)$ disseram que não costumam assistir as gravações. Perguntou-se, também, se o fato de saber que a gravação estará disponível posteriormente desmotiva os discentes a assistir uma aula remota ao vivo (síncrona), e 29 discentes (31,5\%) responderam que sim, enquanto 63 discentes $(68,5 \%)$ disseram que não desmotivou.

O fato das aulas serem gravadas e disponibilizadas aos discentes, prática adotada por boa parte das IES durante a pandemia, não se trata de aproximar-se do ensino à distância, mas de potencializar a ferramenta, buscando proporcionar não só o acesso dos discentes que não acompanharam a aula de forma remota em tempo real, mas permitir aos discentes assistirem, novamente a explicação do professor, e revisar os conteúdos (Barbosa et al., 2020).

Sobre a qualidade da formação acadêmica, 37 discentes $(40,2 \%)$ acreditam que suas formações ficarão prejudicadas de alguma forma por conta da adoção das aulas remotas, mas a maior parte deles ( $\mathrm{n}=55 ; 59,8 \%)$ respondeu que não acredita nesse prejuízo à formação. Para aqueles que responderam "sim" a esta pergunta, foi solicitada uma justificativa, e como as respostas foram dissertativas, houve a necessidade de categorizar as respostas para posterior análise, por meio da categorização proposta por Bardin (2010). Desta forma, as principais justificativas apontadas pelos discentes foram a falta de atividades práticas $(n=22 ; 23,9 \%)$ e a dificuldade para acompanhar as aulas ou se adaptar ao sistema remoto $(n=15 ; 16,3 \%)$.

As aulas práticas compõem uma característica fundamental da graduação em Educação Física, como mostra a Resolução CNE/CNS n n $^{\circ}$, de 18 de dezembro de 2018, a qual cita que a formação específica do Bacharelado, e da Licenciatura em Educação Física deverá envolver atividades práticas como parte do currículo, distribuídas ao longo dos semestres, além dos estágios obrigatórios. Este é um fato que justifica a percepção dos discentes de que a falta de atividades práticas prejudicará a sua formação.

Os discentes declararam utilizar prioritariamente notebooks $(\mathrm{n}=54 ; 58,7 \%)$, smatphones $(\mathrm{n}=52 ; 56,5 \%)$ e computadores $(n=24 ; 26,1 \%)$ para acompanhar as aulas remotas. Sobre os locais de onde estes costumam acompanhar as aulas, destacam-se suas próprias casas $(n=91 ; 98,1 \%)$, casas de amigos ou parentes $(n=11 ; 12 \%)$ e locais de trabalho $(n=7 ; 7,6 \%)$. Perguntou-se aos discentes quais foram as maiores dificuldades para acompanhar as aulas remotas. As respostas mais assinaladas foram, respectivamente: "tive dificuldade com a conexão à internet" (n=62; 67,4\%), "acho este modelo pouco atrativo" (n=26; 28,3\%), "tive problemas pessoais" ( $\mathrm{n}=20 ; 21,7 \%)$ e "não possuo notebook ou outro aparato eletrônico para acompanhar as aulas" ( $\mathrm{n}=10 ; 10,9 \%)$. Vale ressaltar que para esta questão foram aceitas mais de uma alternativa como resposta.

Vergara (2007) aponta a importância da estrutura tecnológica e sua relação com a qualidade, afirmando que a modalidade de ensino remoto é mais sólida nos países desenvolvidos, pois estes investem em ciência e tecnologia, criando 
assim mecanismos eficientes para a otimização da interação professor-aluno, aumentando a qualidade do processo de ensinoaprendizagem. Konrath et al. (2009) destacam a estrutura para o ensino a distância, que engloba todos os recursos materiais e espaciais como relevantes para sustentar a proposta do curso. No ensino à distância, especificamente, é preciso garantir aos estudantes o acesso à internet por meio de polos, além de tutores presenciais, bibliotecas, salas para os encontros presenciais, estrutura e equipamentos para o uso de videoconferências, por exemplo.

Sobre a dificuldade de conexão à internet, sabe-se que este ainda é um problema no Brasil. A Pesquisa Nacional por Amostra de Domicílios Contínua - Tecnologia da Informação e Comunicação de 2018 (PNAD Contínua TIC - 2018), realizada pelo Instituto Brasileiro de Geografia e Estatística (IBGE) e divulgada em 2020 (IBGE, 2020), mostra que uma em cada quatro pessoas no Brasil ainda não possui acesso à internet, número que representa 46 milhões de brasileiros. Dentre as pessoas sem acesso à rede, 11,8\% delas justificam dizendo que o serviço de internet possui um valor elevado, enquanto para 5,7\% delas, o que dificulta é o custo do equipamento necessário para acessá-la (celular, laptop e/ou tablet).

Além disso, os resultados da pesquisa do IBGE indicaram que os aparelhos celulares são a principal ferramenta de acesso à internet no Brasil. Os resultados divergentes entre esta pesquisa e os dados encontrados pelo IBGE podem se justificar pela finalidade do uso. Enquanto a pesquisa do IBGE mostra que a atividade principal utilizada é a troca de mensagens, a finalidade dos discentes é a educação. Para o aluno, acompanhar uma aula pelo celular ou smartphone pode ser ruim quando comparada à possibilidade de acessar por meio de um notebook, por exemplo.

Adicionalmente, as plataformas e aplicativos utilizados para a educação remota são, geralmente, grandes e consomem muitos dados de internet, fazendo-se necessária uma internet de banda larga doméstica de qualidade, ou um plano de dados abrangente, o que acarreta em um maior custo para o usuário. Sobre a utilização de banda larga no país, a conexão móvel (3G ou $4 \mathrm{G}$ ) é a mais utilizada, com um percentual de $80,2 \%$ de usuários, enquanto o percentual de usuários da banda larga fixa gira em torno de $75,9 \%$ (IBGE, 2020).

Sobre a continuidade dos estudos durante o período, 43 discentes (46,7\%) pensaram em trancar a matrícula ou desistir do curso durante o período de aulas remotas, enquanto 49 deles $(53,3 \%)$ disseram que não.

Quando perguntados sobre as maiores dificuldades para os estudos durante o período de aulas remotas, os discentes apontaram a dificuldade na organização do próprio tempo $(n=38 ; 41,3 \%)$, os problemas pessoais $(n=35 ; 38 \%)$ e as dificuldades financeiras $(n=30 ; 32,6 \%)$.

Sobre a entrega das atividades durante o período de aulas remotas, foi questionado se os discentes tiveram dificuldades em cumprir o prazo, e quais foram os motivos do atraso, e os mais apontados foram: "problemas com acesso à internet" ( $\mathrm{n}=35 ; 38 \%)$, "dificuldade ao acessar a plataforma virtual de aprendizagem" ( $\mathrm{n}=24 ; 26,1 \%)$, "dificuldades para organizar meu tempo de estudo e cumprir com os prazos" ( $\mathrm{n}=25 ; 27,2 \%)$ e "problemas pessoais" ( $\mathrm{n}=20 ; 21,7 \%)$.

Sobre o compromisso dos discentes, é importante ressaltar que no ensino remoto, o aluno não pode assumir uma postura passiva. Em outras palavras, o aluno precisa fazer mais do que apenas acessar o ambiente, assistir as aulas e ler o conteúdo disponibilizado. Nesta mudança, o discente precisa entender e aprender sobre o que é ser um aluno virtual, além de desenvolver o compromisso, a organização, a autonomia, a disciplina e a iniciativa (Konrath et al., 2009).

Vergara (2007) destaca alguns dos pontos positivos do ensino remoto, como o desenvolvimento da independência do aluno e o comportamento proativo e da autodisciplina na busca de seu desenvolvimento. Mas, alerta que, para isso, é necessário que o aluno desenvolva a autonomia responsável, monitorando a si próprio e sabendo pedir ajuda quando necessária.

Além disso, a dificuldade no manuseio das plataformas e dos ambientes AVAs não é apenas dos docentes, mas também dos discentes. Vergara (2007) diz que a baixa capacidade operacional do computador, a lentidão no acesso à 
plataforma e a falta de flexibilidade do programa, bem como a falta de habilidade dos discentes para lidarem com a informática e com as metodologias, podem configurar-se como pontos negativos do ensino online.

Sobre as questões financeiras, Schenatz et al. (2019) explicam que a realidade brasileira possui algumas particularidades, como a taxa significativa de evasão das instituições de ensino superior devido a dificuldades financeiras. Para os autores, as desigualdades sociais do Brasil acabam exigindo a formação universitária visando mais oportunidades aos jovens no mercado de trabalho. Por outro lado, há um grande número de estudantes com dificuldades financeiras, e que precisam de trabalhar para pagar o curso, e contam com o apoio institucional, que é fundamental. Diante da COVID-19, o estudo realizado por Menezes Filho e Komatsu (2020) mostrou que cerca de 37 milhões de pessoas trabalham em setores que estão sendo diretamente afetados pelos longos períodos de quarentena.

Diante da situação causada pela COVID-19, a vida das pessoas foi afetada de muitas formas, o que justifica o número de discentes alegando problemas pessoais e dificuldades durante o período de aulas remotas. Além dos impactos econômicos, as consequências físicas e psicológicas também devem ser consideradas. Em Hong Kong e no Irã, por exemplo, foram constatados aumentos no nível de ansiedade da população frente à pandemia. (Kwok et al., 2020; Moghanibashi-Mansourieh, 2020).

Na China, país onde a doença surgiu, o estudo de Wang et al. (2020), realizado com 1.210 sujeitos de 194 cidades, durante a fase inicial do surto de COVID-19, apontou que mais da metade dos entrevistados classificaram o impacto psicológico da doença entre moderado a grave, e que cerca de um terço dos respondentes relatou ansiedade moderada a grave. Em outro estudo, realizado por Huang e Zhao (2020) com 7.236 participantes, registrou-se a prevalência de sintomas de ansiedade, depressão e má qualidade do sono com percentual de $35,1 \%, 20,1 \%$ e $18,2 \%$, respectivamente. Os autores destacaram que os profissionais de saúde e os mais jovens (menores de 35 anos) corriam um risco especialmente alto de apresentar impactos psicológicos quando passavam muito tempo pensando sobre a doença.

Por fim, foram feitas duas perguntas abertas aos discentes, sobre os pontos positivos e negativos das aulas remotas, quando comparadas às aulas presenciais. Como pontos positivos, destacam-se a possibilidade de assistir aulas gravadas ( $\mathrm{n}=19$; $20,7 \%)$, as questões relacionadas ao conforto do ambiente doméstico $(n=19 ; 20,7 \%)$, o menor dispêndio de tempo e dinheiro com a necessidade de deslocamento $(\mathrm{n}=16 ; 17,4 \%)$, um número menor de distrações em casa que na sala de aula (barulho, conversas paralelas) $(n=10 ; 10,9 \%)$ e a maior flexibilidade para assistir as aulas $(n=7 ; 7,6 \%)$.

Embora destacadas as diferenças entre as modalidades de ensino, os achados vão ao encontro do citado por Vergara (2007) destaca como vantagens do ensino à distância o fato de permitir ao aluno compatibilizar seu curso com suas disponibilidades de tempo, além de realizá-lo no ritmo e velocidade desejados em qualquer local.

Os pontos negativos destacados pelos discentes foram a dificuldade para comunicação e interação com os professores e com os outros discentes $(n=30 ; 32,6 \%)$; as dificuldades de conexão $(n=23 ; 25 \%)$; a falta de aulas e atividades práticas $(n=18$; 19,6\%); aulas pouco atrativas ou monótonas ( $\mathrm{n}=9 ; 9,8 \%)$; e as distrações do ambiente doméstico $(\mathrm{n}=7 ; 7,6 \%)$. Demarco e Honorato (2013) corroboram com os achados deste estudo e apontam como uma desvantagem do ensino à distância o fato deste não proporcionar uma relação "face-a-face" entre o aluno e o professor, característica marcante do ensino presencial.

Para Vergara (2007), esta questão de relacionamento está vinculada à efetividade humana. Para a autora, esta é uma questão cultural, já que no Brasil valorizam-se os contatos próximos, onde o aluno precisa sentir que o professor se relaciona com ele. Além disso, a questão do feedback é apontada por alguns autores como uma limitação do ensino remoto (Vasconcellos \& Bergamaschi, 2001).

Na educação online, o feedback individual e instantâneo continua sendo um fator determinante para a aprendizagem, mas é relevante considerar que neste ambiente, o foco é a criação de uma sala de aula interativa, em que todos os participantes 
interagem com todos, desta forma, professores e discentes, pois esta configuração não permite alunos passivos e/ou professores centralizadores (Santos \& Silva, 2019).

Diante deste atual cenário, Rasheed et al. (2020) ressaltam que a autorregulação e uso da tecnologia são os principais desafios que os estudantes enfrentam. Em relação aos professores, o principal desafio está no uso da tecnologia para o ensino. Por fim, o fornecimento de tecnologia instrucional adequada e o apoio efetivo à formação de professores são os principais desafios enfrentados pelas instituições de ensino (Rasheed et al., 2020).

\section{Considerações Finais}

De acordo com os resultados do presente estudo, pode-se considerar que a percepção e a avaliação dos estudantes investigados sobre a adoção das aulas remotas frente a suspensão das atividades presenciais causada pela COVID-19 são, de forma geral, positivas. A maior parte dos discentes entende que a decisão da instituição foi acertada, assim como avalia de forma positiva o trabalho desenvolvido pelos docentes.

Embora os discentes considerem que os professores fizeram um trabalho satisfatório, é importante destacar que uma parcela significativa destes não acredita que o modelo remoto de ensino seja atrativo, e/ou que indicaram uma diminuição no próprio interesse em acompanhar as aulas ao longo do tempo, ou ainda que, enxergam como um fator negativo desta modalidade de ensino a falta do contato e a dificuldade para a comunicação interpessoal. Estes resultados demonstram o quanto é relevante os docentes estarem atentos às formas de apresentação dos conteúdos durante as aulas, evidenciando o valor da adoção de inovações nas propostas metodológicas e visando a interação.

No entanto, a importância da formação complementar dos professores, a preparação para a utilização de ferramentas tecnológicas, assim como para o desenvolvimento de novas possibilidades pedagógicas. Frente a COVID-19, muitas instituições de ensino superior e seus docentes não tiveram tempo hábil para esta preparação, o que pode representar uma limitação para o sucesso do ensino remoto. Ainda, muitos docentes apresentam dificuldades na utilização das ferramentas e da própria plataforma das aulas.

Além disso, destaca-se também um grande número de respostas indicando as dificuldades financeiras e pessoais, assim como a conexão à internet, como empecilhos para o acompanhamento das aulas. Logo, além do apoio aos docentes é necessário que as instituições estejam atentas à estas questões, buscando novas políticas e medidas para auxílio a estes estudantes, seja ele financeiro, estrutural, logístico ou acadêmico, principalmente devido a crise econômica e aos desempregos gerados pela pandemia.

Apontamos como limitação do presente estudo o fato de ser um estudo de caso, e portanto, ter sido conduzido apenas com estudantes de um único curso de graduação; a unicidade de uma instituição de ensino. Verificamos ainda algumas limitações do próprio instrumento utilizado, como a falta de uma especulação mais profunda sobre questões financeiras, por exemplo. Assim, sugerimos estudos futuros, que possam considerar outras realidades (instituições de ensino, cursos ou países), assim como a percepção de outros envolvidos no processo de ensino-aprendizagem. Sugere-se, por fim, a coleta de outros dados relevantes, como a renda dos discentes ou valor da mensalidade, para que possam ser traçadas outras relações.

\section{Referências}

André, M. (2013). O que é um estudo de caso qualitativo em Educação? Revista da FAEEBA - Educação e Contemporaneidade, 22 (40), 95-103. 10.21879/faeeba2358-0194.2013.v22.n40.p95-103

Barbosa, A. M., Viegas, M. A. S., \& Batista, R. L. N. F. F. (2020). Aulas presenciais em tempos de pandemia: relatos de expe riências de professores do nível superior sobre as aulas remotas. Revista Augustus, 25 (51), 255-280. 10.15202/1981896.2020v25n51p255

Bardin, L. (2010). Análise de conteúdo: Edições 70. 
Decreto $N^{\circ}$ 9.057, de 25 de maio de 2017. (2017). Regulamenta o art. 80 da Lei $\mathrm{n}^{\circ}$ 9.394, de 20 de dezembro de 1996, que estabelece as diretrizes e bases da educação nacional. http://www.planalto.gov.br/ccivil_03/_ato2015-2018/2017/decreto/d9057.htm

Center for Disease and Prevention (CDC) (2019). Coronavirus disease (COVID-19): Social Distancing, Quarantine, and Isolation. https://www.cdc.gov/coronavirus/2019-ncov/prevent-getting-sick/social-distancing.html.

Cetron, M., \& Simone, P. (2004). Battling 21st-century scourges with a 14th-century toolbox. Emerging Infectious Diseases, 10 (11), 2053-2054. 10.3201/eid1011.040797_12

Demarco, S. R. S., \& Honorato, H. G. (2013). A Educação a distância e a tutoria: alguns olhares. In Anais do Seminário Internacional de Educação a Distância (pp. 206-2016), Belo Horizonte, MG, Brasil.

Huang, Y. \& Zhao, N. (2020). Mental health burden for the public affected by the COVID-19 outbreak in China: who will be the high-risk group? Psychology, Health and Medicine, 1 (12), 1-13. 10.1080/13548506.2020.1754438

Instituto Brasileiro de Geografia e Estatística (IBGE). (2020). PNAD Contínua TIC 2018: Internet chega a 79,1\% dos domicílios do país. https://agenciadenoticias.ibge.gov.br/agencia-sala-de-imprensa/2013-agencia-de-noticias/releases/27515-pnad-continua-tic-2018-internet-chega-a-79-1-dosdomicilios-do-pais

Konrath, M. L. P., Tarouco, L. M. R., \& Behar, P. A. (2009). Competências: desafios para discentes, tutores e professores da EaD. CINTED-UFRG, 7 (1), 110. $10.22456 / 1679-1916.13912$

Kwok, K. O., Li, K. K., Chan, H. H., Yi, Y. Y., Tang, A., Wei, W. I., \& Wong, Y. (2020). Community responses during early phase of COVID-19 epidemic, Hong Kong. Emerging Infectious Diseases, 26 (7), 1-13, 2020. 10.3201/eid2607.200500

Lewnard, J. A., \& Lo, N. C. (2020). Scientific and ethical basis for social-distancing interventions against COVID-19. The Lancet Infectious Diseases, 20 (6), 631-633. 10.1016/S1473-3099(20)30190-0

Mattar, F. N. Pesquisa de marketing: edição compacta: Atlas, 1996.

Menezes Filho, N. A., \& Komatsu, B. K. (2020). Simulações de impactos da COVID-19 e da renda básica emergencial sobre o desemprego, renda e pobreza e desigualdade. Policy Paper, 43, 1-31. https://www.insper.edu.br/wp-content/uploads/2020/04/Policy-Paper-v14.pdf

Ministério da Saúde. (2020). Sobre a Doença, 2020. https://coronavirus.saude.gov.br/sobre-a-doenca\#o-que-e-covid

Moghanibashi-Mansourieh, A. (2020). Assessing the anxiety level of iranian general population during COVID-19 outbreak. Asian Journal of Psychiatry, 51, (102076), 1-5. 10.1016/j.ajp.2020.102076

Moran, J. M. (2003) Contribuições para a pedagogia da educação online. In Silva, M. (Org.). Educação online: teorias, práticas, legislação, formação corporativa. (pp. 41-52): Edições Loyola.

Rasheed, R. A., Kasmin, A., \& Abdullah, N. A. (2020). Challenges in the online componente of blended learning: a systematic review. Computers \& Education, v.144, n. 103701. 10.1016/j.compedu.2019.103701

Resolução CNE/CNS $n^{o}$ 6, de 18 de dezembro de 2018. (2018). Institui Diretrizes Curriculares Nacionais dos Cursos de Graduação em Educação Física e dá outras providências. http://portal.mec.gov.br/index.php?option=com_docman\&view=download\&alias=104241-rces006-18\&category_slug=dezembro-2018pdf\&Itemid=30192

Santos, E. dos. (2017). Educação online como dispositivo na ciberpesquisa-formação. Revista Tecnologias na Educação, 20, 1-9. http://tecedu.pro.br/wpcontent/uploads/2017/10/Art9-vol.20-Edi\%C3\%A7\%C3\%A3o-Tem\%C3\%A1tica-IV-Outubro-2017.pdf

Santos, E. dos, \& Silva, I. P. da. (2019). A topografia da sala de aula online: reflexões a partir de uma experiência de pesquisa-formação com professores de ciências. Caderno Brasileiro de Ensino de Física, 36 (1), 204-223, 2019. 10.5007/2175-7941.2019v36n1p204

Schenatz, B. N., Cunha, M. A. V. C., \& Kugler, J. L. C. (2019). Smart Campus e Analytics na gestão de instituições de ensino superior para redução da ev asão e promoção da permanência. Revista Inteligência Competitiva, 9 (2), 82-101. 10.24883/ric.v9i2.323

Schimiguel, J., Fernandes, M. E., \& Okano, M. T. (2020). Investigando aulas remotas e ao vivo através de ferramentas colabora tivas em período de quarentena e Covid-19: relato de experiência. Research, Society and Development, 9 (9), e654997387. 10.33448/rsd-v9i9.7387

Silva, M. (2012). Criar e professorar um curso online: relato de experiência. In Silva, M. (Org.). Educação online: teorias, práticas, legislação, formação corporativa. (pp. 53-76): Edições Loyola.

Silva, T. M. O da, Silva, K. R. G. da, Sousa, R. P. de; Silva, Y. P. E. da, \& Macedo, S. A. de. (2020). Conceitos dos discentes de enfermagem sobre aulas remotas. Revista Diálogos em Saúde, 3 (1), 47-61. http://periodicos.iesp.edu.br/index.php/dialogosemsaude/article/view/275/235

Stake, R. E. (2011). Pesquisa qualitativa: estudando como as coisas funcionam: Penso.

Vasconcellos, L., \& Bergamaschi, S. (2001). Equipes virtuais. In Anais dos Seminários em Administração, São Paulo, SP, Brasil.

Vergara, S. C. (2007). Estreitando relacionamentos na educação a distância. Cadernos EBAPE.BR, 5 (esp.), 1-8. 10.1590/S1679-39512007000500010

Wang, C., Pan, R., Wan, X., Tan, Y., Xu, L., Ho, C. S., \& Ho, R. C. (2020). Immediate psychological responses and associated factors during the initial stage of the 2019 coronavirus disease (covid-19) epidemic among the general population in China. International Journal of Environmental Research Public Health, 17 (5), p. 1729. 10.3390/ijerph17051729 
Research, Society and Development, v. 10, n. 4, e3510413843, 2021

(CC BY 4.0) | ISSN 2525-3409 | DOI: http://dx.doi.org/10.33448/rsd-v10i4.13843

Wilder-Smith, A., \& Freedman, D. O. (2020). Isolation, quarantine, social distancing and community containment: Pivotal role for old-style public health measures in the novel coronavirus (2019-nCoV) outbreak. Journal of Travel Medicine, 27 (2), 1-4. 10.1093/jtm/taaa020 